\title{
Roentgen cephalometric analysis of ridge resorption and changes in jaw and occlusal relationships in immediate complete denture wearers
}

\author{
A. TALLGREN, B. R. LANG, G. F. WALKER and M. M. ASH, JR \\ University of Michigan, School of Dentistry and Dental Research Institute, \\ Ann Arbor, Michigan
}

\section{Summary}

In eighteen subjects assigned for immediate complete upper and lower dentures, roentgen cephalometric recordings were made before extraction of the residual anterior dentition and 3 weeks, 3 months, 6 months and 1 year after denture insertion. The cephalometric analysis was based on electronic measurements of linear and angular morphological variables and computer head plots generated from 177 reference points (Walker, 1967), derived for each subject for each of the five observation stages.

The reduction of the alveolar ridges was most rapid during the first 3 months of denture wear and particularly during the post-extraction period of 3 weeks. The reduction in anterior height of the lower ridge was on average twice as great as that of the upper ridge. The ridge resorption and the accompanying settling of the dentures on the basal seats, measured from lead shots inserted in the dentures, brought about an upward rotation of the mandible with a resulting decrease in occlusal vertical dimension and reduction in overjet of the dentures. In accordance with the amount of ridge reduction, these changes showed great individual variation.

\section{Introduction}

The reduction of the alveolar ridges after extraction of teeth and insertion of complete dentures has been well documented in roentgen cephalometric and model studies of various categories of denture wearers (Atwood, 1957; Tallgren, 1957, 1967, 1969, 1972; Watt, 1960; Watt \& Likeman, 1974; Johnson, 1963, 1964a, b, c, 1967; Wictorin, 1964; Carlsson, Bergman \& Hedegård, 1967 ;Carlsson \& Persson, 1967; Atwood \& Coy, 1971; Winter, Woelfel \& Igarashi, 1974; Michael \& Barsoum, 1976).

The long-term reduction of the residual ridges and the effect of the ridge resorption on jaw and occlusal relationships was investigated by Tallgren $(1967,1969,1972)$ in samples of Finnish subjects provided with conventional complete dentures after a healing period of some 3 months. The reduction in occlusal vertical dimension, characteristic for complete denture wearers, was found to be mainly due to a marked resorption of the lower ridge with a resulting upward rotation of the mandible and an

Correspondence: A. Tallgren, University of Michigan, School of Dentistry, Department of Occlusion, Ann Arbor, Michigan 48109, U.S.A.

$$
\text { 0305-182X/80/0100-0077 \$02.00 (C) } 1980 \text { Blackwell Scientific Publications }
$$


increase in mandibular prognathism. A pronounced resorption, particularly of the lower ridge was observed in individuals with a facial type characterized by a marked bend of the mandibular base, and less marked resorption in subjects with a flattened mandibular base.

In order to examine the pattern of maxillary and mandibular ridge resorption in individuals provided with immediate complete dentures and the effect of the ridge reduction on facial morphology and jaw muscle activity, a longitudinal roentgen cephalometric and electromyographic investigation was initiated at the University of Michigan School of Dentistry in 1975. The aim of this paper is to present roentgen cephalometric findings on alveolar ridge resorption during 1 year of denture wear and the effect of the ridge reduction on jaw and occlusal relationships.

\section{Materials and methods}

The sample consisted of eighteen subjects, eight women and ten men, registered for immediate complete denture treatment at the University of Michigan School of Dentistry and willing to participate in the follow-up examinations. The age range of the sample was 24-69 years and the mean age 50.4 years. Fifteen of the subjects were Caucasians and three American blacks. None of the subjects gave a history of any diagnosed disease which might have affected the skeletal structures.

The stages of observation were the following:

I. Before extraction of the residual dentition.

II. After insertion of immediate complete upper and lower dentures: on average 3 weeks after insertion when the patients felt comfortable with the dentures and did not complain of sore spots.

III. Three months after denture insertion.

IV. Six months after insertion.

V. One year after insertion.

Prior to the first recording, the subjects, as a rule had had all their molars and second premolars extracted; some patients were also missing the first premolars.

Two of the subjects were not able to attend the 3-month examination but attended the 6-month check. The 1-year follow-up was completed by fifteen subjects, the reduction by three persons being due to moving out of the area or difficulties in attending due to working conditions.

\section{Denture construction}

The immediate complete dentures for the subjects of study were made by dental students supervised by the Complete Denture departmental staff and were constructed according to a standardized technique.

The procedure in construction of the dentures was as follows: preliminary impressions for study models were taken in alginate. For the final maxillary impression a sectional acrylic resin tray was constructed and for the mandibular impression a one piece acrylic resin tray. The borders of the trays were moulded in dental compound to determine flange length and thickness. Mercaptan polysulphide rubber base material was used as final wash material for the maxillary posterior segments, while for recording of the anterior residual dentition irreversible hydrocolloid was used. The mandibular arch was recorded using the one piece tray and Mercaptan polysulphide rubber base material as final wash material.

The recordings of vertical dimension and centric jaw relation were made according 
to customary procedures at the department, using acrylic resin baseplates stabilized by tinfoil and rubber base impression material. When occlusal stops were present, and verified for accuracy, they were used as guides for determination of the vertical dimension of occlusion.

The posterior teeth used for the dentures were zero degree $31 \mathrm{~mm}$ acrylic resin teeth and only three teeth, one bicuspid and two molars, were used in each quadrant. The posterior teeth were set to a flat plane without compensating curves and without protrusive balance. The anterior teeth were set with as low an incisal guidance as possible without destroying the aesthetics.

Before delivery of the dentures three small lead shots were inserted in the maxillary and mandibular denture: one in the mid-line, posteriorly and cervically to the central incisors, and two in the posterior area, on the right and left side immediately distal to the last molars.

The surgery at the delivery of the immediate dentures consisted of extraction of the remaining teeth with little or minimal alveolectomy. The dentures were remounted some 10 days after delivery to re-establish centric occlusion. The post-insertion cephalometric recordings were performed as soon as the patient was comfortable with the dentures, as a rule 3 weeks after surgery. A clinical examination of the dentures was made at all follow-up stages and relining was performed when necessary.

\section{Radiographic procedure}

At all stages of observation lateral head films were taken in the standing position by use of a vertically adjustable head holder, a Wehmer cephalostat*, coupled to the $\mathrm{X}$-ray source. The focus-film distance was $5 \mathrm{ft}(152.4 \mathrm{~cm})$ and the distance from the mid-sagittal plane to the film was kept constant at $17 \mathrm{~cm}$. This gave a linear enlargement of $11 \cdot 2 \%$. In the measurements performed on the X-ray films, no corrections were made for the enlargement.

In taking the cephalometric films the position of the head was orientated according to its natural balance and the patient was looking at his/her eyes in a mirror in front of the cephalostat (Solow \& Tallgren, 1971). An $0.9 \mathrm{~mm}$ tin-lead wire suspending a weight was mounted in front of the cassette in order to indicate the true vertical on the film.

At each session one film was taken in centric occlusion and two in mandibular postural position (Tallgren, 1957). At the denture stages the rest position films were taken with and without the dentures in the mouth, and the occlusion films in biting from the postural position to maximal occlusal contact. In the present study only the occlusion films were analysed.

\section{Methods of measurement}

The measurements on the radiographs were made according to the method introduced by Walker (1967), with slight modifications to suit the present longitudinal project. Thus, of the original 177 reference points (Fig. 1), some points were omitted in order to include certain special reference points for measurements of the alveolar resorption (Tallgren, 1967), the position of the hyoid bone, and some points on the cervical vertebrae and the true vertical defined by Solow \& Tallgren (1971) for later analysis of the position of the head and cervical column. 




Fig. 1. Basic roentgen cephalometric reference points (177 points) on the lateral cephalometric films for measurements of craniofacial morphology and deriving of computer generated head plots. Modified from Walker \& Kowalski (1971).

In accordance with the procedure described by Walker \& Kowalski (1971), tracings of the craniofacial structures were made from the occlusion films taken at the different stages of observation. Double contours of bilateral structures were bisected. To facilitate marking of the reference points on the tracings (Fig. 1), a reference line of orientation was drawn from Occipitale (pt 16) to the midpalatal point Maxillon (pt 135). The tracings were positioned on a $x$ and $y$ co-ordinate grid with the Sella point at zero and the $x$-axis parallel to the orientation line. The locating and marking of the reference points was checked by three persons.

An estimate of the accuracy of locating and marking the cephalometric reference points on the tracings was obtained by Walker (1969). This was done by calculating the dispersion for twenty-four conventional anatomical points from a series of ten tracings of one cephalogram, made by three laboratory technicians. The largest range of dispersion between the three operators for twenty-four points was from $0 \cdot 24$ to $1.08 \mathrm{~mm}$.

The present recordings of the $x$ and $y$ co-ordinates of the reference points was made with an Edwin Industries Corporation Digitizer Model PF 40. The output of the digitizer is accurate to the nearest $1 / 1000$ of an inch $(0.025 \mathrm{~mm})$. The co-ordinate 
values were recorded on cards through direct linkage to an IBM Model 29 card punch and the data were then transferred to a computer memory (AMDAHL/V6).

Using the Retscan (Retrieval and Scanning) program provided by the Biometrics Laboratory, head plots based on the 177 reference points were derived for each

Table 1. Reference points and lines on the cephalometric films (numbers within brackets refer to number of points in Fig. 1)

\begin{tabular}{|c|c|c|}
\hline \multicolumn{3}{|c|}{ Reference points } \\
\hline ans & $(132)$ & The apex of the anterior nasal spine \\
\hline$a r$ & $(148)$ & $\begin{array}{l}\text { Articulare. The intersection between the external contour of the cranial base and the } \\
\text { dorsal contour of the condyle }\end{array}$ \\
\hline$b a$ & (13) & Basion. The most postero-inferior point on the anterior margin of foramen magnum \\
\hline$g n$ & (139) & $\begin{array}{l}\text { Point on mandibular symphysis obtained by bisecting the right angle formed by } \\
\text { the tangents to the chin and mandibular base }\end{array}$ \\
\hline go & $(144)$ & $\begin{array}{l}\text { The point on the bony contour of the gonial process obtained by bisecting the angle } \\
\text { formed by the tangents to the mandibular base and ramus (RL) }\end{array}$ \\
\hline id & $(136)$ & $\begin{array}{l}\text { Infradentale. The most superior point on the anterior contour of the mandibular } \\
\text { alveolar process }\end{array}$ \\
\hline if & $(112)$ & Inframalar point. The most inferior point on the shadow of the malar bone \\
\hline$\ddot{i i}$ & $(166)$ & $\begin{array}{l}\text { Incision inferius. The midpoint of the incisal edge of the most prominent lower } \\
\text { central incisor* }\end{array}$ \\
\hline is & $(162)$ & $\begin{array}{l}\text { Incision superius. The midpoint of the incisal edge of the most prominent upper } \\
\text { central incisor* }\end{array}$ \\
\hline$m a$ & $(135)$ & $\begin{array}{l}\text { Maxillon. Midpoint on the palate in the vertical direction projected from the in- } \\
\text { framalar point (112) }\end{array}$ \\
\hline me & $(140)$ & Menton. The most inferior point on the mandibular symphysis \\
\hline$m o l^{i}$ & $(177)$ & Inferior molar point. The disto-buccal cusp of the first lower molar* \\
\hline $\mathrm{mol}^{\mathrm{s}}$ & $(173)$ & Superior molar point. The disto-buccal cusp of the first upper molar* \\
\hline$m p$ & $(125)$ & Projection of inframalar point on the inferior contour of hard palate \\
\hline  & $(58)$ & Nasion. The most anterior point of the frontonasal suture \\
\hline occ & $(16)$ & Occipitale. The most inferior point on the occipital bone \\
\hline$p g$ & $(138)$ & Pogonion. The most anterior point on the mandibular symphysis \\
\hline pns & $(127)$ & Posterior nasal spine. The most posterior point on the hard palate \\
\hline pos & $(161)$ & $\begin{array}{l}\text { The intersection between the posterior contour of mandibular symphysis and a line } \\
\text { through pg parallel to ML }\end{array}$ \\
\hline$p r$ & $(134)$ & $\begin{array}{l}\text { Prosthion. The most inferior point on the anterior contour of the maxillary alveolar } \\
\text { process }\end{array}$ \\
\hline$s$ & $(95)$ & $\begin{array}{l}\text { Sella point. The centre of sella turcica. The upper limit of sella turcica is defined as } \\
\text { the line joining the tuberculum and dorsum sellae }\end{array}$ \\
\hline$s m$ & $(137)$ & $\begin{array}{l}\text { Supramentale (B point). The most posterior point on the anterior contour of the } \\
\text { mandibular alveolar process }\end{array}$ \\
\hline$s s$ & $(133)$ & $\begin{array}{l}\text { Subspinale (A point). The most posterior point on the anterior contour of the maxil- } \\
\text { lary alveolar process }\end{array}$ \\
\hline
\end{tabular}

Reference lines

ML

MLP

NSL

OLi

OLs

PL

PLP

REF

RL
Mandibular line. The line through go (144) and gn (139)

Mandibular line perpendicular. The perpendicular to ML through pg (138)

Nasion-sella line. The line through $n(58)$ and $s$ (95)

Lower occlusal line. The line through ii (166) and mol (177)

Upper occlusal line. The line through is (162) and $\mathrm{mol}^{s}$ (173)

Palatal line. The line through ans (132) and pns (127)

Palatal line perpendicular. The perpendicular to PL through ans (132)

Reference line of orientation. The line through occ (16) and ma (135)

Ramus line. The tangent to ramus mandibulae through ar (148)

* On the denture teeth the point was indicated by a lead strip. 
patient for each of the five observation stages. A check of the recorded points was performed by superimposition of the head plots from each stage on the respective tracings. To illustrate morphologic changes between observation stages, a serial computer head plot from the five stages was generated for each subject by superimposition of the structures of the skull and maxilla (Figs 5 and 6) with outputs in different colours.

\section{Variables studied}

The reference points and lines used in the present study for measurements of facial morphology are defined in Table 1 and shown in Fig. 2.

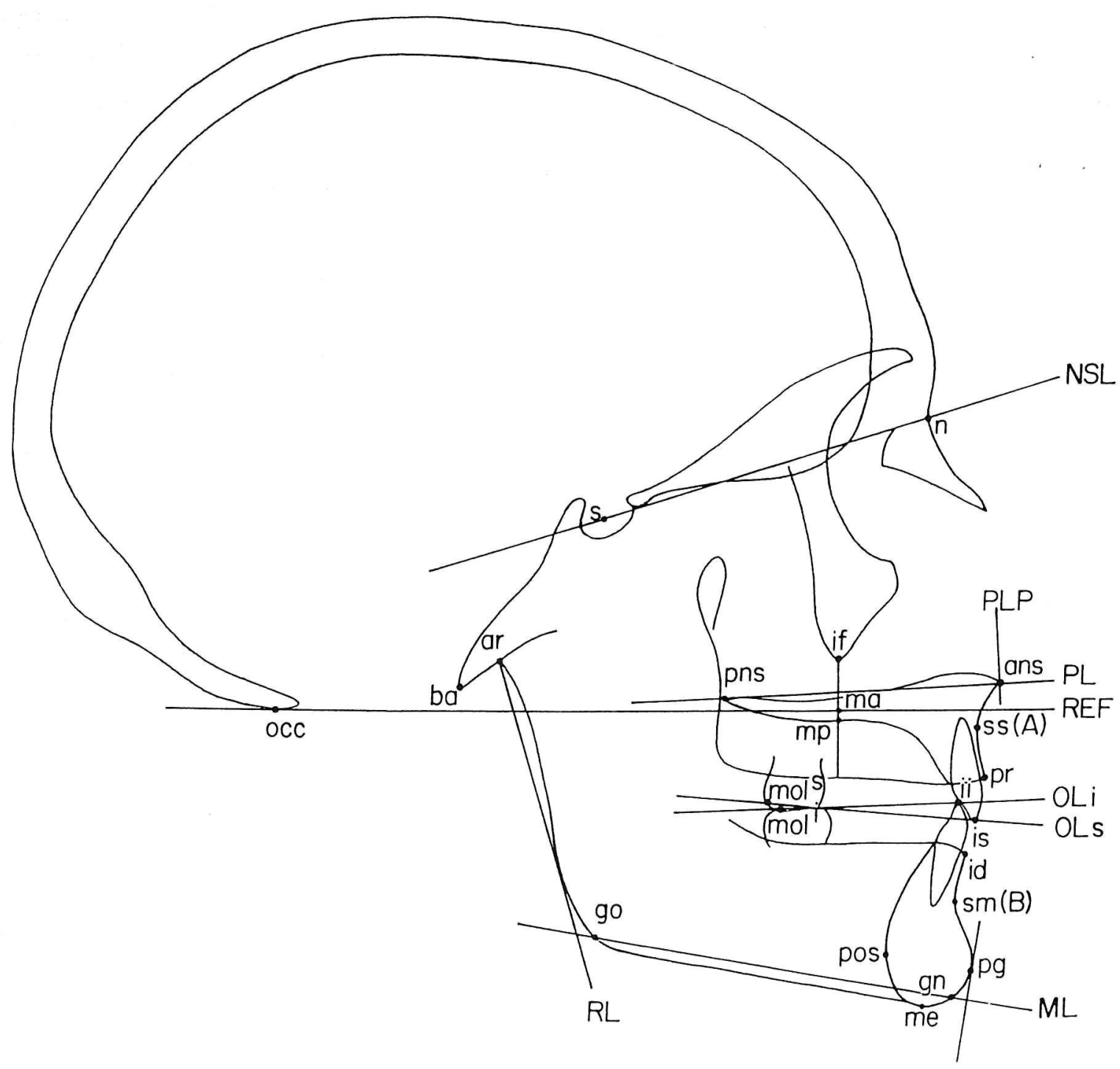

Fig. 2. Reference points and lines on the cephalometric films for measurements of changes in jaw and occlusal relationships.

Regarding measurements of anterior occlusion in the natural dentition and at the denture stages (Table 4), the vertical position of the upper and lower incisal edges in relation to the maxilla (is vert. max. and $i i$ vert. max.) was defined as the perpendicular distance from these points to the reference line, REF, and the horizontal position (is hor. max. and $i i$ hor. max.) as the distance from these points to a perpendicular to REF through maxillon (135). The overjet was determined as the horizontal distance is-ii parallel with REF, and overbite as the vertical distance between these points 
parallel to the perpendicular to REF. The vertical position of the lower incisors in relation to the mandibular base was measured as the perpendicular distance from point $i i$ to ML, and the horizontal position as the distance from ii to MLP.

The reference points used for measurements of alveolar resorption are shown in Fig. 3. On the contour of the maxillary bony ridge, point $m x 1$ was defined as the most inferior-posterior point on the tuberosity, and $m \times 5$ as the point of intersection between the horizontal and palatal ridge contours. Point $m x 6$ was defined as the most inferior point on the top of the maxillary anterior ridge in relation to PL. The horiziontal locations of points $m x 2,3$ and 4 were obtained from film stage I by dividing the distance between $m x I$ and $m x 5$ into four equal segments using a template and projecting these points on PL. For definition of $m x 7$ see $p r$ Table 1.

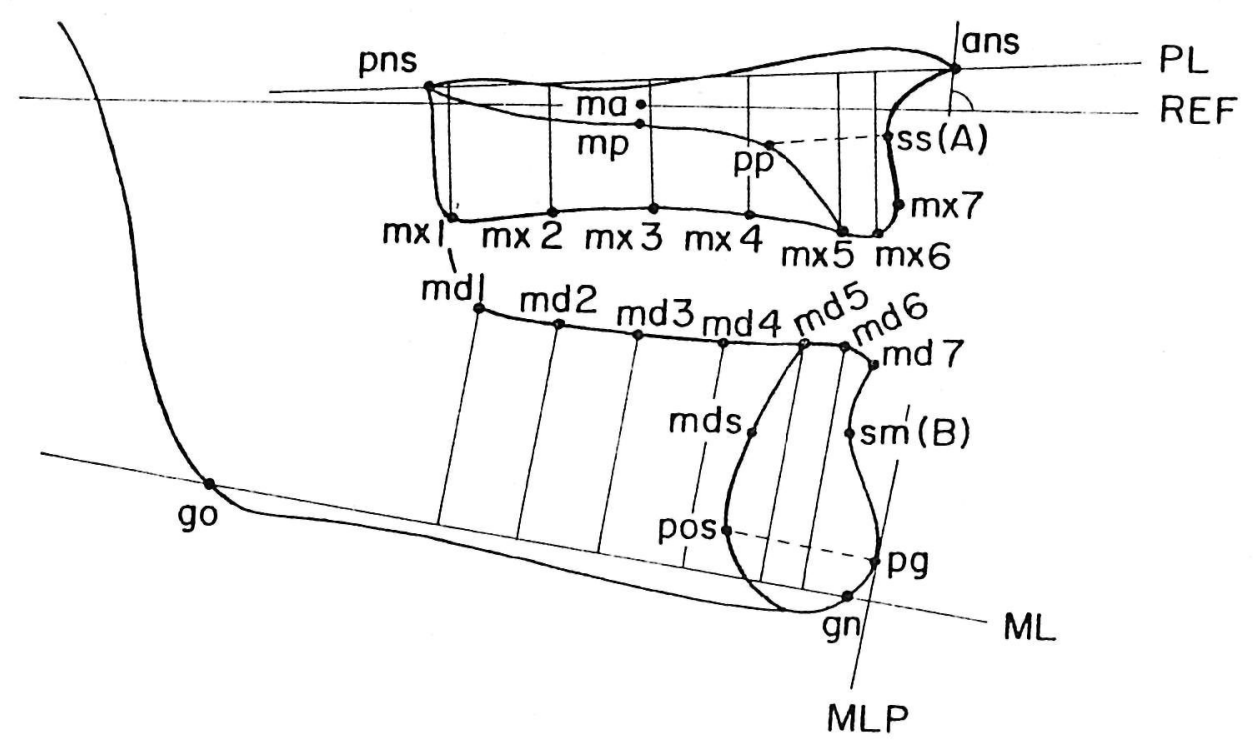

Fig. 3. Reference points and lines on the cephalometric films for measurements of alveolar ridge resorption.

On the contour of the mandibular bony ridge, point $m d 1$ was defined as the most posterior-inferior point of the retromolar fossa, and $m d 5$ as the most superiorposterior point on the mandibular symphysis. Point $m d 6$ was defined at the uppermost point on the symphysis in relation to ML. For definition of $m d 7$, see id Table 1 . The horizontal locations of points $m d$ 2, 3 and 4 were obtained from film stage I by dividing the distance between $m d 1$ and $m d 5$ in four equal segments and projecting these points on ML (Fig. 3).

The linear vertical reduction of the maxillary ridge between observation stages was determined as the difference in height of the process measured at the seven points, $m x l$ to $m x 7$, perpendicular to PL. The reduction in height of the mandibular ridge was measured at the points $m d 1$ to $m x 7$ perpendicular to ML.

The anterior horizontal resorption of the maxillary ridge was measured from points $m x 5, m x 6$ and $m x 7$ to a perpendicular to the reference line REF through ans. The horizontal reduction of the anterior mandibular ridge was measured from points $m d 5, m d 6$ and $m d 7$ to the mandibular line perpendicular (MLP).

For estimating the area of resorption of the maxillary ridge in the anterior region, the area determined by the points $s s$ (A-point), $m \times 7, m \times 6, m \times 5$ and $p p$ was computed for the different observation stages. The area resorption of the anterior mandibular 
ridge was computed from measurements of the area determined by the points pos, $m d s, m d 5, m d 6, m d 7, s m$ (B-point) and $p g$ (Fig. 3). Point $p p$ on palatal contour of the maxillary ridge is the mid-point between $m p$ and $m x 5$, and point $m d s$ on posterior contour of mandibular symphysis is the mid-point between pos and $m d 5$.

The settling of the dentures on the basal seats was measured from the lead shot reference points inserted in the dentures (cf. p. 79). The anterior vertical settling of the maxillary denture was determined as the reduction of the perpendicular distance from the anterior maxillary lead shot point to PL, and the posterior settling as the mean reduction of the perpendicular distances from the two posterior lead shot points to PL. The antero-posterior changes of the maxillary denture were measured from the anterior lead shot point to the palatal line perpendicular (PLP). The anterior settling of the mandibular denture was determined as the reduction of the perpendicular distance from the anterior lead shot point to $M L$, and the posterior settling as the mean reduction of the perpendicular distances from the two posterior lead shot points to ML. The antero-posterior changes of the mandibular denture were measured from the anterior lead shot point to mandibular line perpendicular (MLP).

\section{Statistical analysis}

The values of the linear and angular cephalometric variables were computed from the recorded $x$ and $y$ co-ordinates of the reference points by use of Program Retscan No. 16. The statistical analysis of the data was performed according to MIDAS, the Michigan Interactive Data Analysis System (Fox \& Guire, 1977), and was carried out at the Statistical Unit of the Dental Research Institute by using the Michigan Terminal System.

For each subject the variables from the various stages were computed, as well as the differences in variables between the observation stages. For the statistical description of the variables the conventional parameters and the form of the distributions were employed. In testing the significance of the mean differences between the observation stages the paired $t$-test was used.

\section{Results}

The mean differences in the variables studied between the observation stages are shown in Tables 2-4. The mean changes reported in the following sections are all significant at the $5 \%$ or $1 \%$ levels unless otherwise stated.

\section{Changes in anterior occlusion due to denture construction}

Comparison of the position of the denture central incisors at the post-insertion stage with that of the natural incisors (Table 4, stage II-I, and Fig. 4) revealed that the upper denture incisors were positioned on the average $1.4 \mathrm{~mm}$ more upward (is vert. max.) and $1.3 \mathrm{~mm}$ more outward (is hor. max.) than the natural teeth. The differences were significant at the $5 \%$ level. The incisal edges of the lower denture incisors were positioned on the average $1.9 \mathrm{~mm}$ lower (ii ML) and $2.6 \mathrm{~mm}$ more labially (ii MLP) than the natural teeth. The overjet which in the natural dentition showed a mean of $4.3 \mathrm{~mm}$ was reduced in the dentures by a mean of $1.7 \mathrm{~mm}$, and the overbite which in the natural dentition showed a mean of $4.9 \mathrm{~mm}$ was reduced by a mean of $4 \mathrm{~mm}$.

The occlusal vertical dimensions after denture insertion as compared with that in the natural dentition (n-me, ans-me, stage II-I), showed individual variations of slight increases and decreases, the average change being a non-significant increase of $0.3 \mathrm{~mm}$. 


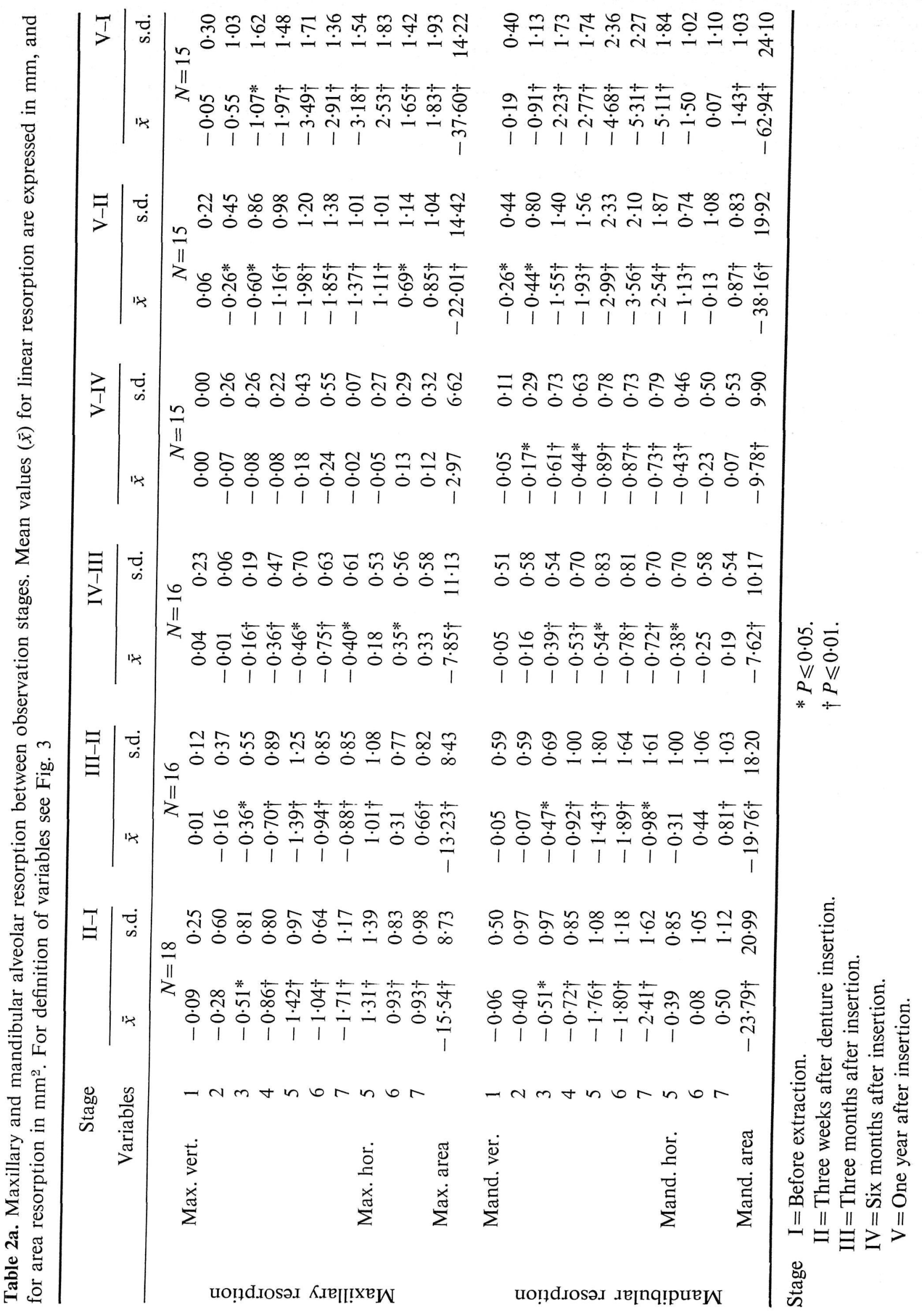


Table 2b. Mean rate of reduction (mm/month) in anterior height of the maxillary and mandibular alveolar ridges (points $m x 6$ and $m d 6$ )

\begin{tabular}{|c|c|c|c|}
\hline \multirow[b]{3}{*}{ Stage } & \multicolumn{3}{|c|}{ Rate of reduction ( $\mathrm{mm} /$ month) } \\
\hline & & Maxilla & Mandible \\
\hline & $N$ & $\bar{x}$ & $\bar{x}$ \\
\hline II-I & 18 & $1 \cdot 40$ & $2 \cdot 40$ \\
\hline III-I & 16 & $0 \cdot 67$ & $1 \cdot 24$ \\
\hline IV-III & 16 & $0 \cdot 25$ & $0 \cdot 26$ \\
\hline V-IV & 15 & $0 \cdot 04$ & $0 \cdot 15$ \\
\hline V-I & 15 & $0 \cdot 24$ & $0 \cdot 44$ \\
\hline
\end{tabular}

Stage $I=$ Before extraction.

$\mathrm{II}=$ Three weeks after denture insertion.

$\mathrm{III}=$ Three months after insertion.

$\mathrm{IV}=$ Six months after insertion.

$\mathrm{V}=$ One year after insertion.

Table 3. Settling and positional changes of the maxillary and mandibular complete dentures on the basal seats. Mean differences $(\bar{x})$ in $\mathrm{mm}$ and degrees

\begin{tabular}{|c|c|c|c|c|c|c|c|c|c|c|c|c|}
\hline \multirow{2}{*}{$\begin{array}{r}\text { Stage } \\
\text { Variable }\end{array}$} & \multirow[b]{2}{*}{$N$} & \multicolumn{2}{|c|}{ III-II } & \multicolumn{3}{|c|}{ IV-III } & \multicolumn{3}{|r|}{ V-IV } & \multirow[b]{2}{*}{$N$} & \multirow{2}{*}{\multicolumn{2}{|c|}{$\begin{array}{ll} & \text { V-II } \\
\bar{x} & \text { s.d. }\end{array}$}} \\
\hline & & $\bar{x}$ & s.d. & $N$ & $\bar{x}$ & s.d. & $N$ & $\bar{x}$ & s.d. & & & \\
\hline Max. ant. vert. & 15 & $-1 \cdot 19 \dagger$ & 1.08 & 15 & $-0.47 \dagger$ & $0 \cdot 48$ & 14 & $-0 \cdot 29$ & $0 \cdot 51$ & 13 & $-1.95 \dagger$ & $1 \cdot 34$ \\
\hline Max. ant. hor. & & $-0 \cdot 17$ & 0.59 & & $0 \cdot 00$ & $0 \cdot 50$ & & $-0 \cdot 32$ & 0.61 & & $-0 \cdot 58^{*}$ & 0.79 \\
\hline Max. post. vert. & & $-0.51 \dagger$ & $0 \cdot 39$ & & -0.01 & $0 \cdot 47$ & & 0.05 & 0.49 & & $-0 \cdot 45^{*}$ & 0.67 \\
\hline Mand. ant. vert. & & $-0.83 \dagger$ & 0.65 & & $-0.70 \dagger$ & $0 \cdot 88$ & & $-0.79 \dagger$ & $0 \cdot 83$ & & $-2 \cdot 19 \dagger$ & $1 \cdot 28$ \\
\hline Mand. ant. hor. & & $-0.63 \dagger$ & $0 \cdot 72$ & & $-0 \cdot 17$ & $0 \cdot 45$ & & $-0.29 *$ & $0 \cdot 43$ & & $-1 \cdot 15 \dagger$ & $0 \cdot 77$ \\
\hline Mand. post. vert. & & $-0.45 \dagger$ & $0 \cdot 38$ & & $-0.53 \dagger$ & 0.68 & & $-0.73 \dagger$ & 0.71 & & $-1 \cdot 55 \dagger$ & $1 \cdot 19$ \\
\hline OLs-PL & 16 & $-0.84 \dagger$ & $0 \cdot 94$ & 16 & $-0.31^{*}$ & 0.48 & 15 & $-0.73 \dagger$ & $0 \cdot 50$ & 14 & $-1 \cdot 89 \dagger$ & $1 \cdot 27$ \\
\hline Oli-ML & & $-0.50 *$ & 0.73 & & $-0 \cdot 16$ & 0.89 & & 0.00 & 0.63 & & $-0 \cdot 61$ & $1 \cdot 20$ \\
\hline
\end{tabular}

\footnotetext{
Stage $\mathrm{II}=$ Three weeks after denture insertion.

$* P \leqslant 0.05$.

III $=$ Three months after insertion.

$\dagger P \leqslant 0 \cdot 01$.

$\mathrm{IV}=$ Six months after insertion.

$\mathrm{V}=$ One year after insertion.
}

However, since the post-insertion examination was made some 3 weeks after denture insertion, the initial alveolar resorption during this interval had influenced the results to some extent.

\section{Resorption of alveolar ridges}

The mean reduction of the maxillary and mandibular bony ridges during the observation periods is shown in Table 2a. For definition of the variables cf. Fig. 3 and pp. 83-84. 


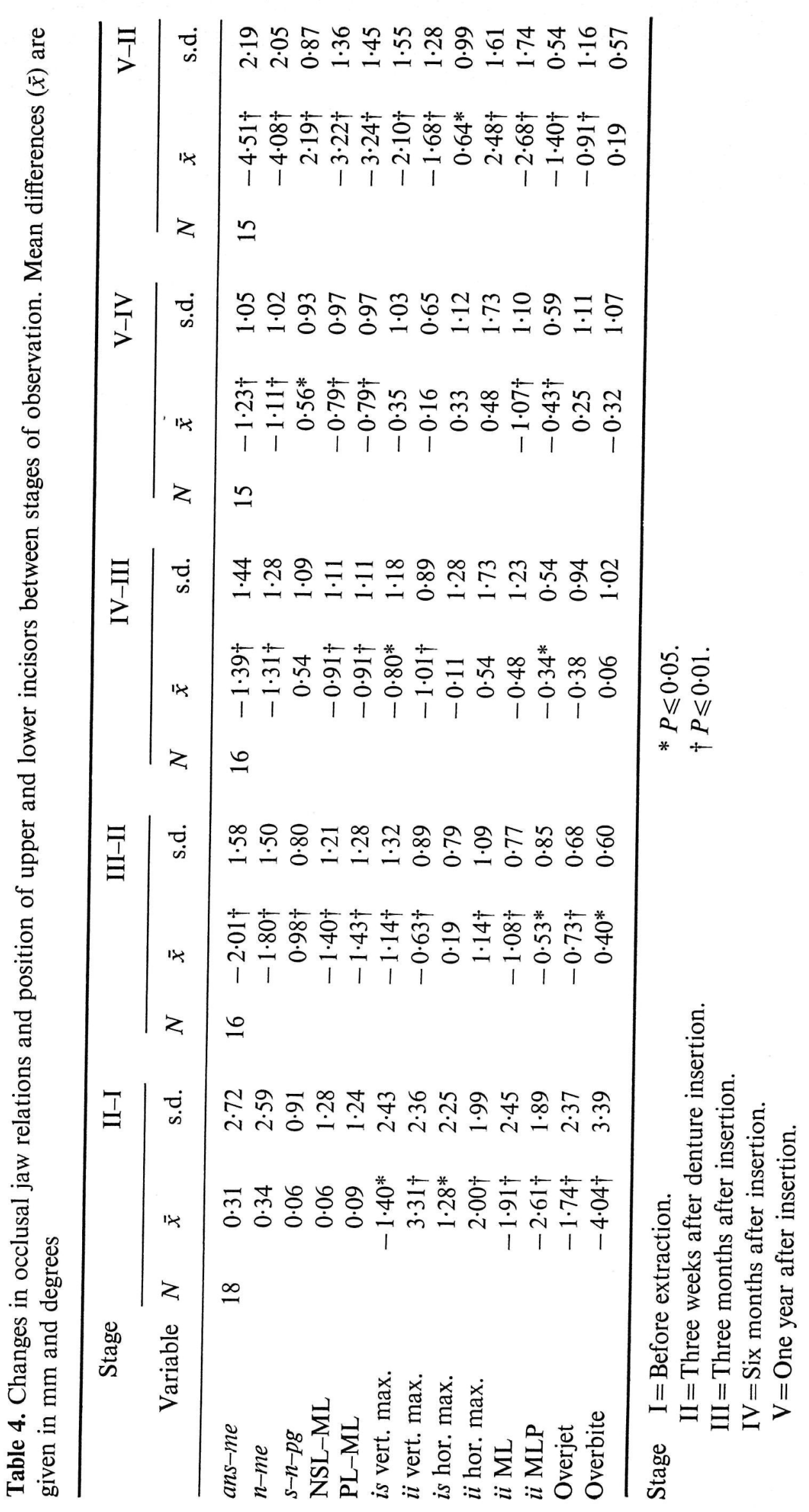




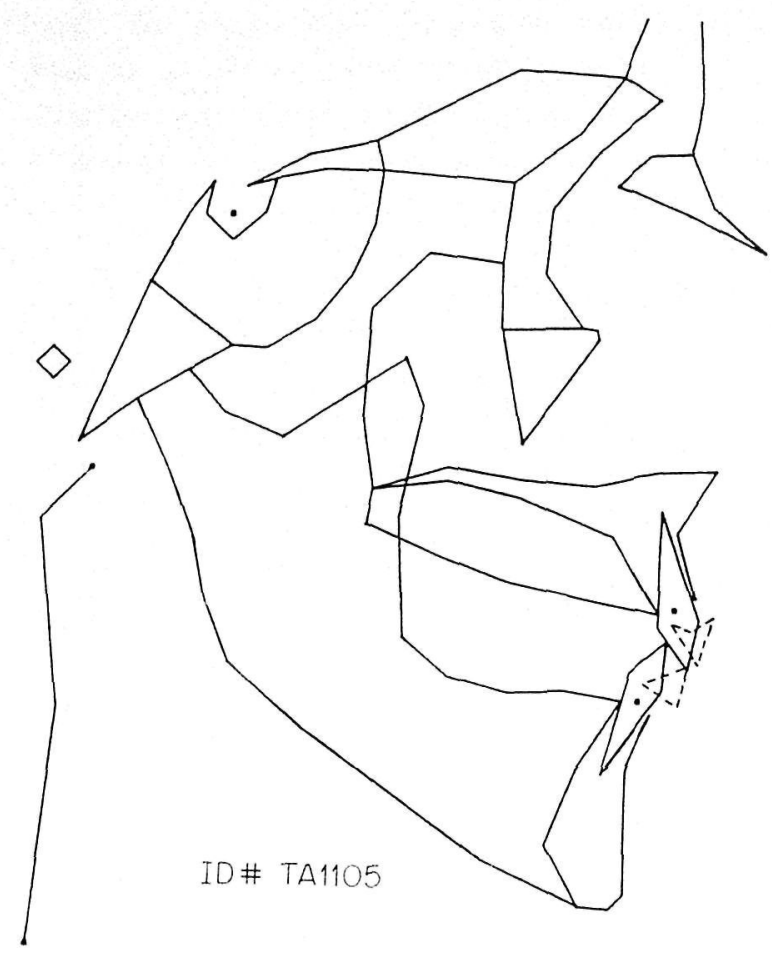

Fig. 4. Head plot illustrating changes in anterior occlusion due to denture construction. The broken line illustrates position of the incisors after denture insertion (stage II) as compared to the natural teeth (solid line).

Comparison of the vertical ridge reduction in the different regions showed that in both jaws the mean reduction was greatest in the anterior part (points $m x 5,6,7$ and $m d 5,6,7)$, from where it gradually decreased posteriorly at points $4,3,2$, and 1 .

The decrease in anterior height of the mandibular ridge ( $m d 6$ ) during the different observation periods was on average about twice as great as that of the anterior maxillary ridge $(m \times 6)$. In the premolar area (points 3 and 4 ) the difference in reduction between the jaws was less marked. In the molar area the reduction of the upper ridge ( $m x 1$ and $m x 2$ ) as a rule was insignificant throughout the observation period, whereas in the lower jaw ( $m d l$ and $m d 2$ ) significant posterior reduction was observed at the 1 -year stage. The rate of the vertical ridge reduction, generally, was fastest during the first 3 months of denture wear and particularly during the initial post-insertion period (II-I), which averaged 3 weeks and represented the post-extraction period (Tables $2 a, b)$.

Regarding the horizontal reduction in the anterior region (Table 2a), the maxillary process displayed, on average, greater resorption on the palatal side $(m \times 5)$ than on the labial side $(m \times 7)$, whereas for the mandibular process the labial resorption ( $m d 7$ ) initially was somewhat greater than the lingual ( $m d$ s). The horizontal reduction of the maxillary ridge was greater in most instances, than that of the mandibular ridge, while the vertical reduction, as previously reported, was on average about half of the mandibular reduction. Due to this difference in resorption pattern between the jaws, the area resorption of the anterior maxillary process was approximately two-thirds of the mandibular resorption area (Table 2a).

The mean reduction in anterior height of the mandibular ridge during 1 year of denture wear ( $m d 6$, stage $\mathrm{V}-\mathrm{I}$ ) was $5.3 \mathrm{~mm}$ and the area resorption $63 \mathrm{~mm}^{2}$. The 
maxillary anterior reduction $(m x 6)$ during 1 year showed a mean of $2.9 \mathrm{~mm}$ and the area reduction a mean of $37.6 \mathrm{~mm}^{2}$.

\section{Settling of the dentures}

The settling of the dentures due to alveolar resorption was measured from the lead shot reference points in relation to the jaw bases (p. 84). The mean values of the positional changes of the dentures are given in Table 3.

At the 3-month stage of denture wear (III-II) the maxillary denture showed a mean vertical settling of $1.2 \mathrm{~mm}$ in the anterior region and a mean posterior settling of $0.5 \mathrm{~mm}$, the forward component of $0.2 \mathrm{~mm}$ being insignificant. For the mandibular denture the anterior settling showed a mean of $0.8 \mathrm{~mm}$ and the posterior settling $0.5 \mathrm{~mm}$, the mean forward displacement of the denture being $0.6 \mathrm{~mm}$.

Between the 3- and 6-month stages (IV-III) the anterior settling of the maxillary denture (mean $0.5 \mathrm{~mm}$ ) was about half of that during the preceding 3-month period and, on average, no posterior settling or horizontal displacement of the denture was displayed. The mandibular denture, on the other hand, showed approximately the same mean values for the settling as during the preceding period, only the forward displacement was less marked and insignificant.

It should be noted that during the first 3 months after insertion, the dentures were relined for two patients, and during the second 3-month period for five more subjects. During the second half year of denture wear, relining was performed for four more patients. In spite of relining of the dentures for more than half the subjects, a continuing significant settling of the mandibular denture was observed at the 1-year stage, although at a diminished rate. The maxillary denture, on the other hand, showed no significant settling during the second half year of denture wear.

The total mean anterior settling of the mandibular denture during 1 year (V-II) was $2.2 \mathrm{~mm}$ and the posterior settling $1.6 \mathrm{~mm}$, with a forward displacement of $1.2 \mathrm{~mm}$. Due to the small difference between the anterior and posterior settling, the mean decrease in inclination of the mandibular occlusal plane (OLi-ML) was only $0.6^{\circ}$ and insignificant. The maxillary denture had settled anteriorly by a mean of $2.0 \mathrm{~mm}$ and posteriorly by $0.5 \mathrm{~mm}$ with a forward displacement of $0.6 \mathrm{~mm}$. Due to the more marked settling in the anterior than in the posterior region, the maxillary occlusal plane (OLs-PL) showed a total mean decrease of $1.9^{\circ}$.

\section{Changes in jaw and occlusal relationships of the dentures}

The alveolar ridge reduction and settling of the dentures on the basal seats brought about a decrease in mandibular inclination (NSL-ML, PL-ML), i.e. a forwardupward rotation of the mandible with a resultant decrease in occlusal vertical dimension (ans-me, $n-m e$ ) and increase in mandibular prognathism, $s-n-p g$ (Table 4, Figs 6 and 7). In accordance with the rate of ridge reduction, the magnitude of these changes were most marked during the first 3 months of denture wear (III-II). The total upward change in mandibular position during 1 year of denture wear (V-II) showed a mean of $3 \cdot 2^{\circ}$, the increase in mandibular prognathism a mean of $2 \cdot 2^{\circ}$ and the decrease in occlusal vertical dimension a mean of $4.5 \mathrm{~mm}$.

The vertical and horizontal changes in position of the upper and lower incisors (is and ii) in relation to the jaw bases are also given in Table 4 . The mean changes correspond well to the values for the positional changes of the dentures (Table 3 ) obtained from the lead shot reference points. Due to the forward-upward rotation of 
the mandible and a greater forward displacement of the lower denture (ii MLP) than that of the upper (is hor. max.), the overjet of the dentures decreased during the observation period, and led in some patients to an anterior cross-bite (Fig. 7). The overbite on the other hand showed only a less marked decrease.

In accordance with the magnitude of alveolar ridge reduction, the changes in jaw and occlusal relationships showed great individual variations (Figs 5 and 6).

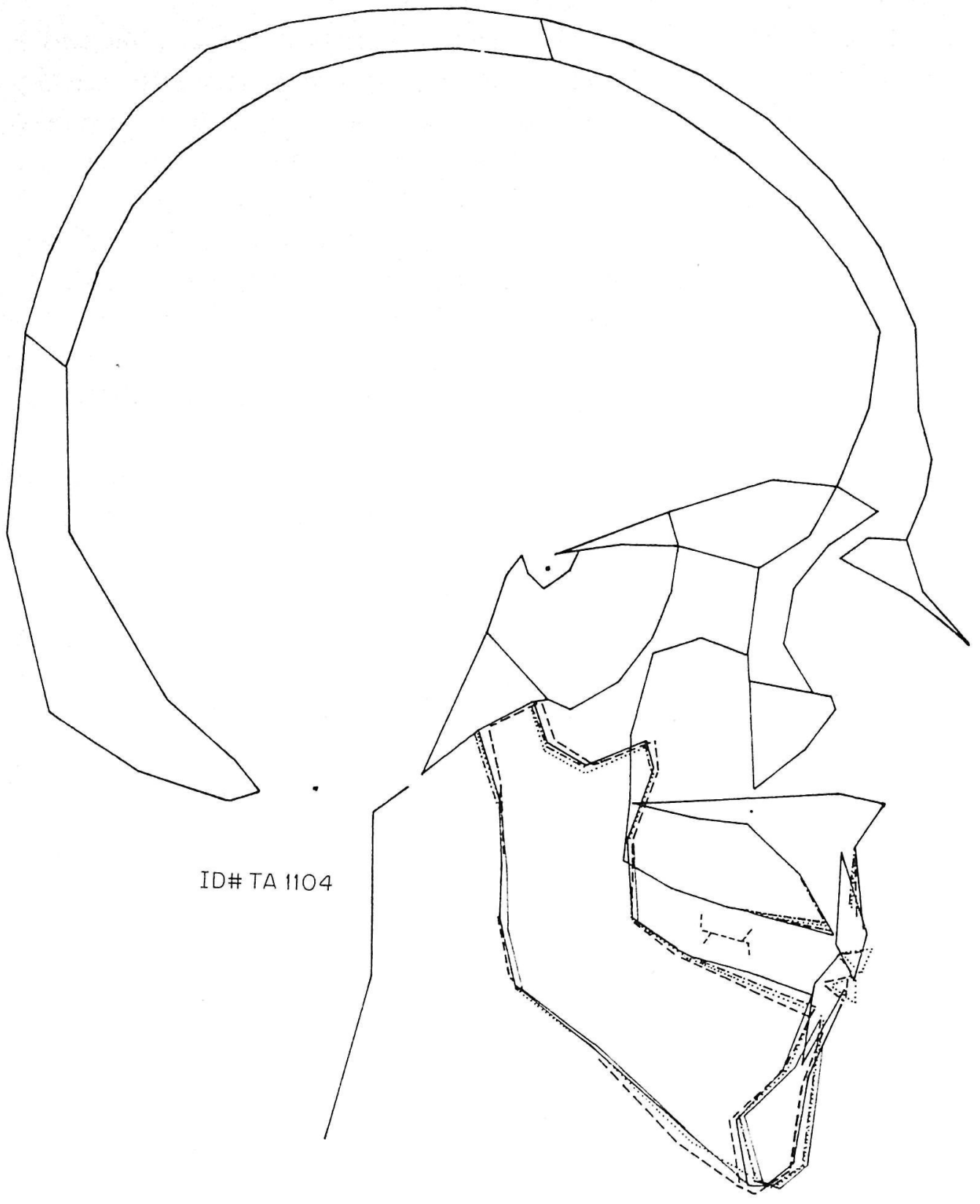

Fig. 5. Tracing of a serial head plot from the five stages of observation derived electronically by superimposition of the structures of the skull and maxilla. The broken line (- - -) illustrates an increase in occlusal vertical dimension after denture insertion (stage II) as compared to the pre-extraction stage (solid line). In this subject the alveolar resorption and changes in jaw and occlusal relationships were slight.

\section{Discussion}

In evaluating the electronic measurement technique for roentgen cephalometric analyses of craniofacial morphology, one of the great advantages is the time saving procedure in comparison with manual measurements. Another important advantage is the possibility of operating with a great number of reference points for computing of head plots and morphological variables covering the whole craniofacial skeleton. By 


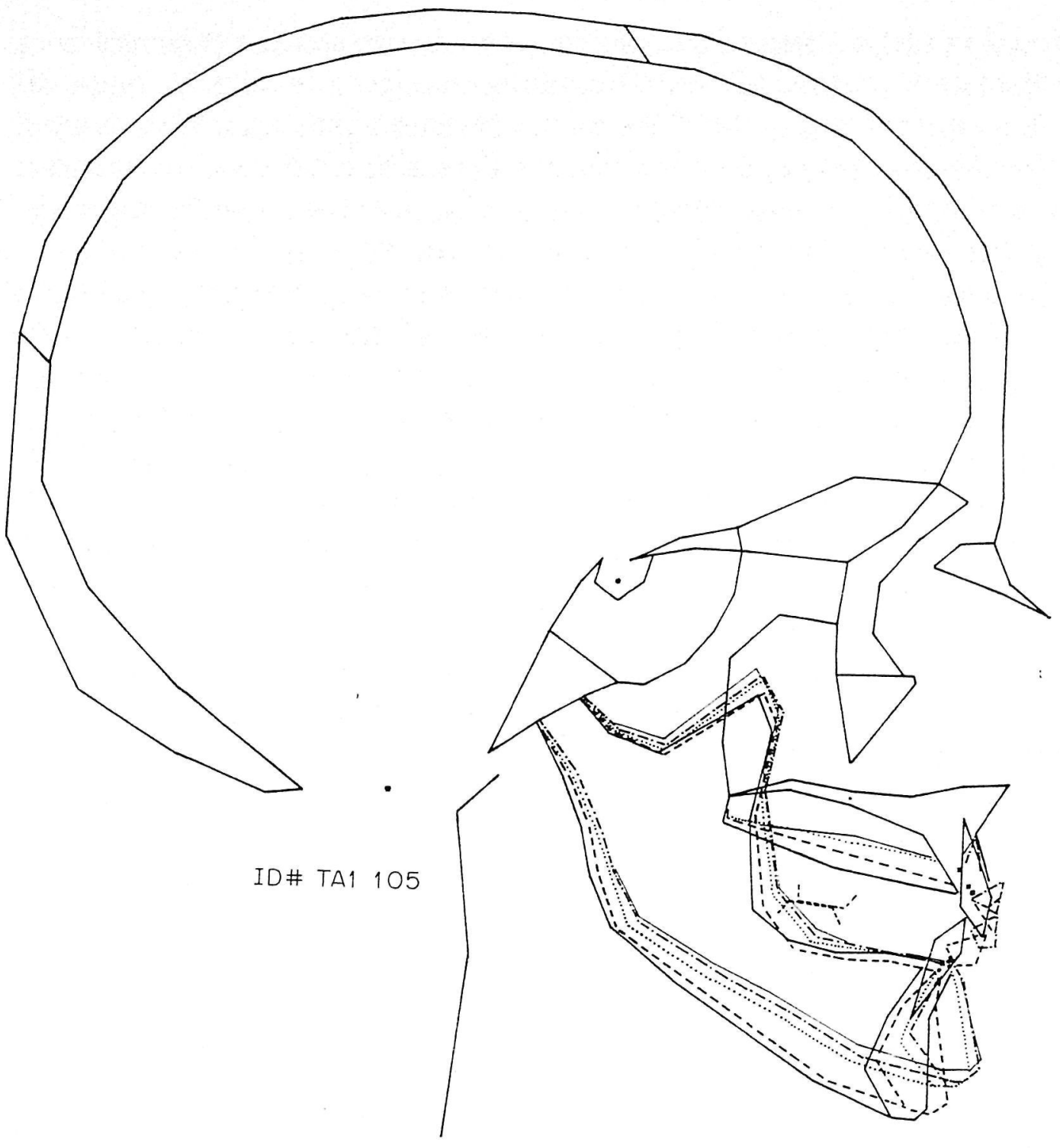

Fig. 6. Tracing of a serial head plot from the five stages of observation derived electronically by superimposition of the structures of the skull and maxilla. Stage I (thick solid line), II (- - - ), III ( . . . ), IV (-.-.-) and V (thin solid line). In this patient the alveolar ridge resorption was pronounced and resulted in a marked upward rotation of the mandible and changes in occlusion of the dentures (cf. Fig. 7).

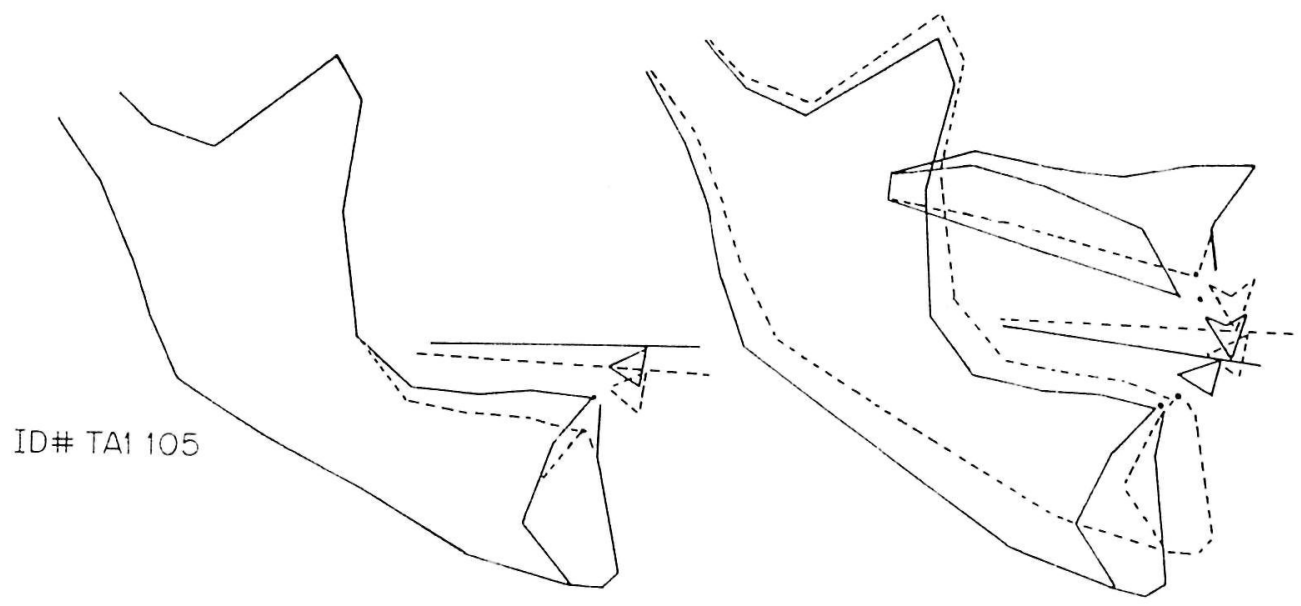

Fig. 7. Same patient as in Fig. 6. Tracings from head plots at the post-insertion stage II (solid line) and the 1-year stage $\mathrm{V}$ (broken line). The figure to the left illustrates the settling of the lower denture due to resorption of the mandibular ridge. The figure to the right shows the forward-upward rotation of the mandible due to alveolar ridge reduction, and the decrease in overjet which in this patient led to a mandibular overjet. 
storing a mathematical model or map of the skull as co-ordinate values of the reference points in a computer memory or on tape, additional desired variables can be computed at any time. For the present longitudinal study, the method introduced by Walker (1967) based on 177 reference points enabled good anatomical head plots to illustrate the resorption of the alveolar ridges and changes in jaw and occlusal relationships and individual variations in morphological changes (Figs 5 and 6).

Regarding the measurement technique, the marking of the cephalometric reference points on tracings of the craniofacial skeleton enables at any time a check on the correct location of the points. The localization of the reference points on the cephalograms is considered to involve the greatest part of method errors in cephalometric measurements (Björk, 1947; Carlsson, 1967; Solow \& Tallgren, 1971). In the present study the locating and marking of the reference points was checked by three persons.

Another advantage of the electronic method, which was also applied in the present study, is that the individual head plots can be used for a quality control, i.e. a check of errors in digitizing of the points from the tracings.

The comparison of the denture occlusion at the post-insertion stage with that in the natural dentition revealed marked changes in position of the upper and lower incisors, which were related to a reduction of the overbite and overjet in construction of the dentures. In evaluation of these changes in anterior occlusion it should be borne in mind that the non-anatomical posterior teeth were set to a flat occlusal plane without compensating curves and without protrusive balance and, consequently, the anterior teeth were set with a low incisal guidance. The mean reduction of the overbite from 4.9 to $0.9 \mathrm{~mm}$ and of the overjet from 4.3 to $2.6 \mathrm{~mm}$ correspond well to average values used at the Complete Denture Department for this type of denture construction.

The alveolar resorption in the present sample was generally fastest during the first 3 months of denture wear, the post-extraction reduction during the early healing period being particularly pronounced. This is in accordance with previous observations on the rate of ridge reduction in immediate denture wearers and in subjects provided with conventional complete dentures (Johnson, 1963, 1964a, b, c, 1967; Wictorin, 1964; Tallgren, 1967, 1969, 1972; Carlsson et al., 1967; Carlsson \& Persson, 1967; Michael \& Barsoum, 1976).

Regarding the reduction in height of the bony ridges, the findings of a more marked reduction in the anterior region of the process is in accordance with previous observations by Tallgren (1969) and confirms the findings by Carlsson \& Persson (1967) that the magnitude of mandibular reduction decreases with the distance from pogonion.

The mean reduction in anterior height of the mandibular ridge during the 1-year observation period was found to be about twice as great as that of the upper ridge. This is in agreement with observations by Tallgren (1969) in subjects provided with conventional complete dentures. However, long-term observations by Tallgren (1969, 1972) and Atwood \& Coy (1971) indicate that during protracted wearing of dentures the ratio between the mandibular and maxillary reductions increases to about $4: 1$. As stated previously (Tallgren, 1967, 1972) the most likely reason for the great resorption of the mandibular ridge is the smaller area and less advantageous shape of the lower basal seat. In regard to the less marked resorption of the upper ridge, the resistance offered by the palate to the influences of the functional forces through the denture on the alveolar ridge most likely plays an important part. 
The mean reduction in anterior maxillary height during 1 year $(2.9 \mathrm{~mm})$ is within the range of means $2-4 \mathrm{~mm}$ reported in studies of subjects provided with immediate or conventional complete upper dentures (Wictorin, 1964; Tallgren, 1969). The mean reduction in height of the anterior mandibular ridge during 1 year $(5.3 \mathrm{~mm})$ was somewhat higher than the means around $4 \mathrm{~mm}$ reported in samples with immediate or conventional complete lower dentures (Carlsson \& Persson, 1967; Tallgren, 1969). Regarding the antero-posterior resorption of the maxillary ridge, the finding that the mean reduction on the palatal side was more marked than that on the labial side is in accordance with observations by Carlsson et al. (1967) in samples with immediate complete dentures. Michael \& Barsoum (1967), on the other hand, found more marked labial than palatal resorption under maxillary immediate dentures in comparing different surgical procedures for removal of the anterior teeth.

The present finding that the horizontal resorption in the anterior region of the maxillary ridge was on the average greater than the vertical reduction is in accordance with observations by Johnson $(1963,1964 a, b, c)$. Furthermore, the observation that the vertical mean reduction of the anterior mandibular ridge was greater than the horizontal resorption is in agreement with the study by Carlsson \& Persson (1967). The difference in behaviour between the upper and lower dentures in chewing and biting (Smith, Kydd \& Wykhuis, 1963) may be contributory factors to the difference in site of resorption displayed by the maxillary and mandibular prccesses.

The magnitude and pattern of alveolar resorption in the present sample displayed great individual variations, which are discussed in a separate analysis (Tallgren et al., in prep.). Similar observations have been reported in the various longitudinal studies on alveolar ridge resorption in denture wearers referred to previously.

The settling of the dentures on the basal seats and the resultant changes in jaw and occlusal relationships, basically, displayed the same patterns as shown by Tallgren (1969) in a sample with conventional complete dentures inserted some 3 months after the extractions. However, due to the difference in type of denture treatment, the mean values from the two studies are not quite comparable. Moreover, in the abovementioned study by Tallgren no relining of the dentures had been performed, whereas in the present study the dentures were relined for more than half the subjects. The present findings that the complete dentures, and particularly the lower denture, continued to settle in spite of relinings is in accordance with observations by Brigante (1965) in a study of immediate complete denture wearers.

From a clinical point of view, the present study further confirms the necessity of regular controls and early adjustments of the dentures in order to prevent marked changes in jaw and occlusal relationships, caused by the alveolar resorption.

The aim of the continuing study is further to analyse the individual variations in alveolar resorption and the relationship of the ridge reduction to craniofacial morphological characteristics and occlusal factors.

\section{Acknowledgment}

This work was supported by USPHS grant DE 02731.

\section{References}

Atwood, D.A. (1957) A cephalometric study of the clinical rest position of the mandible. Part II. The variability in the rate of bone loss following the removal of occlusal contacts. Journal of Prosthetic Dentistry, 7, 544. 
Atwood, D.A. \& Coy, W.A. (1971) Clinical, cephalometric and densitometric study of reduction of residual ridges. Journal of Prosthetic Dentistry, 26, 280.

BృöRK, A. (1947) The face in profile. Svensk tandläkaretidskrift, 40, Suppl. 5B.

BRIGANTE, F.R. (1965) A cephalometric study of the settling and migration of dentures. Journal of Prosthetic Dentistry, 15, 277.

Carlsson, G.E. (1967) Error in X-ray cephalometry. Odontologisk tidskrift, 75, 99.

Carlsson, G.E., Bergman, B. \& HedegÅRD, B. (1967) Changes in contour of the maxillary alveolar process under immediate dentures. Acta odontologica scandinavica, 25, 1.

Carlsson, G.E. \& Persson, G. (1967) Morphologic changes of the mandible after extraction and wearing of dentures. Odontologisk revy, 18, 27.

Fox, D.J. \& GuiRE, K.E. (1976) Documentation for MIDAS. Statistical Research Laboratory, University of Michigan, Ann Arbor, Michigan.

JoHnson, K. (1963) A study of the dimensional changes occurring in the maxilla after tooth extraction. Part I. Normal healing. Australian Dental Journal, 8, 428; Part II. (1964a) Closed face immediate denture treatment. Australian Dental Journal, 9, 6; Part III. (1964b) Open face immediate denture treatment. Australian Dental Journal, 9, 127; Part IV. (1964c) Interseptal alveolectomy and closed face immediate denture treatment. Australian Dental Journal, 9, 312.

Johnson, K. (1967) A three-year study of the dimensional changes occurring in the maxilla following immediate denture treatment. Australian Dental Journal, 12, 152.

Michael, C.G. \& BARsoum, W.M. (1976) Comparing ridge resorption with various surgical techniques in immediate dentures. Journal of Prosthetic Dentistry, 35, 142.

SMITH, D.E., KydD, W.L. \& WyKhuIs, W.A. (1963) The mobility of artificial dentures during comminution. Journal of Prosthetic Dentistry, 13, 839.

Solow, B. \& Tallgren, A. (1971) Natural head position in standing subjects. Acta odontologica scandinavica, 29, 591.

TAllgren, A. (1957) Changes in adult face height due to ageing, wear and loss of teeth and prosthetic treatment. Acta odontologica scandinavica, 15, Suppl. 24.

TALlgRen, A. (1967) The effect of denture wearing on facial morphology. Acta odontologica scandinavica, 25, 563.

TAllgren, A. (1969) Positional changes of complete dentures. Acta odontologica scandinavica, 27, 539.

TALlgREN, A. (1972) The continuing reduction of the residual alveolar ridges in complete denture wearers: a mixed-longitudinal study covering 25 years. Journal of Prosthetic Dentistry, 27, 120.

WALKER, G.F. (1967) Summary of a research report on the analysis of craniofacial growth. New Zealand Dental Journal, 63, 31.

WALKer, G.F. (1969) Analysis of skull shapes by electronic methods. Technical report to NIH. Philadelphia Center for Research and Child Growth, University of Pennsylvania, Philadelphia, Pennsylvania.

WALKER, G.F. \& KowALSKI, C.J. (1971) A two-dimensional co-ordinate model for the quantification, description, analysis, prediction and simulation of craniofacial growth. Growth, 35, 191.

WAtT, D.M. (1960) Morphological changes in the denture bearing area following the extraction of maxillary teeth. Ph.D. Thesis, University of Edinburgh.

WatT, D.M. \& Likeman, P.R. (1974) Morphological changes in the denture bearing area following the extraction of maxillary teeth. British Dental Journal, 136, 225.

Wictorin, L. (1964) Bone resorption in cases with complete upper denture. Acta radiologica, Suppl. 228.

Winter, C.M., Woelfel, J.B. \& Igarashi, T. (1974) Five-year changes in the edentulous mandible as determined on oblique cephalometric radiographs. Journal of DentalResearch, 53, 1455. 
This document is a scanned copy of a printed document. No warranty is given about the accuracy of the copy. Users should refer to the original published version of the material. 